\title{
Precision Retail Marketing Strategy Based on Digital Marketing Model
}

\author{
Guoan Zhu ${ }^{1,}$, Xue Gao ${ }^{2}$ \\ ${ }^{1}$ Consumer Device Sales Group, Microsoft (China) Co., Ltd., Shanghai, China \\ ${ }^{2}$ College of Management, University of Massachusetts, Boston, USA
}

\section{Email address:}

guoan.zhu@outlook.com (Guoan Zhu)

${ }^{*}$ Corresponding author

\section{To cite this article:}

Guoan Zhu, Xue Gao. Precision Retail Marketing Strategy Based on Digital Marketing Model. Science Journal of Business and Management. Vol. 7, No. 1, 2019, pp. 33-37. doi: 10.11648/j.sjbm.20190701.15

Received: March 18, 2019; Accepted: April 29, 2019; Published: May 23, 2019

\begin{abstract}
In the context of digital marketing mode, the traditional retail industry encounters unprecedented impact and competitive edges of traditional marketing are disappearing. Therefore, this paper comprehensively explores and analyzes retail precision marketing strategies on the basis of digital marketing mode. This paper firstly analyzes predicament of China's retail industry during its development process briefly, plans implementation measures for precision marketing in retail industry in details, and finally analyzes retail precision marketing strategies in the digital marketing mode from three aspects of customer segmentation in marketing, market basket positioning and targeted customer marketing through actual precision marketing applications.
\end{abstract}

Keywords: Digital Marketing Mode, Retailing, Precision Marketing

\section{Introduction}

In recent years, China has officially entered the big data era with the development of science and technology and the increase of digital application. Under this background, the marketing mode in all industries has changed a lot. Retail industry is one of the fastest growing industries in China's traditional industries. Faced with the digital marketing model, traditional retail industry has encountered unprecedented impact. The competitive advantage of traditional marketing ideas has gradually disappeared. If we do not change the marketing ideas and still adopt traditional marketing strategies, then the local retail industry will not be able to stand firm in the fierce market competition. Therefore, it is necessary to study the precise marketing of retail business in order to build the core competitiveness.

From three aspects of individual, organization and customer, Binbin Zheng (2019) chooses the influencing factors around the new characteristics of management in the era of retail digitalization, and constructs a theoretical model of "influencing factors - store creativity - store performance" [1]. Geng Feng and other business representatives (2019) believe that new technologies such as big data and AI are of great significance in driving digital innovation in enterprises [2]. Zheng Zhao (2018) concludes that the digitalization of retail elements and the intellectualization of retail business operation are crucial to the improvement of enterprise performance by studying the impact of Suning's smart retail strategy on its sales performance [3]. ZijianZ hang, Chuanli Xue (2016) believe that the whole channel supply chain is the perfect integration of the whole channel and the supply chain, which can fundamentally improve the core competitiveness of retail enterprises, and has strong adaptability in reducing operating costs, strengthening service level and improving customer satisfaction [4]. Fabin Zhao (2016) believes that with the development of broadband, wireless and mobile Internet, the number of people shopping through mobile intelligent terminals is exploding. In view of the new consumer experience and demand, retail enterprises must make a digital transformation to better serve consumers, otherwise they can only be eliminated in the increasingly competitive market [5].

Based on the digital marketing model, this paper explores the retail precision marketing strategy comprehensively. 
Firstly, it analyses the predicament faced by the traditional retail industry from the aspects of commodity and consumer, sales technology and sales thinking. Then it analyses the implementation strategy of precision marketing in retail industry in detail. Finally, it takes the actual application case of precision marketing in the market to analyze the digital marketing mode from three aspects: customer segmentation in marketing market, positioning of shopping basket and targeted customer marketing. The applicability of retail precision marketing strategy is analyzed. This paper demonstrates that under the background of the current new retail, using data technology, changing the traditional marketing mode, implementing precise marketing strategy, accurately gathering Limited marketing resources to valuable customers, and establishing a new marketing mode are of great significance for the realization of long-term sustainable development among retailers, suppliers and customers..

\section{Predicament of China's Retail Industry During Its Development Process}

\subsection{Predicament in Goods and Customers}

With the continuous improvement of living standard of residents and in the context that people's demands in material life have been basically met, people's pursuits for spiritual life and ideal life have been also improved [6]. In this psychological state, people's shopping and consumption demands also are changed to diversified, personalized and multi-layered ones. And the consumption psychology, consumption method, consumption level and consumption structure is also changed driven by consumer demands. And most importantly, consumer demands also present a feature of transience. It is unfavorable for the retail industry. Therefore, retail enterprises must keep up with the times, constantly meet consumer demands and provides customers with goods timely [7]. In addition to the upgrading problem of consumer demands, the problem of homogenization of physical retail also has serious influence on most physical retail enterprises and caused that retail enterprises lose their existing competitive advantages.

\subsection{Predicament in Sales Technology and Sales Thinking}

The E-commerce develops rapidly in the mode of Internet and there are many pure E-commerce enterprises. It has caused great impact on physical retail enterprises and many traditional pure physical retail enterprises have to resort to transformation and upgrading. However, pure E-commerce enterprises also have their own problems actually. It means that enterprises must realize the full and deep integration online and offline to really provide better experience for customers and meet their actual demands in the new era. For example, Suning.com launches the pick-up service in stores to lead customer flow. At present, this integration still stays in the beginning stage; thus, the deeper and full integration is still needed. Besides, the retail industry still maintains the traditional marketing mode at present and does not form the customer-oriented thinking mode [8]. As a terminal market, the retail industry will be caught in a vicious circle in development and have difficulty in realizing sustainable development if it cannot recognize the importance of consumer demand information.

\section{Analysis of Implementation Measures for Precision Marketing in Retail Industry}

According to the analysis above and the current development situation of China, the retail industry has entered the era of small profits. Under this background, retail enterprises must do their best to solve abovementioned four problems, correctly know the essence of marketing, find and meet customers' actual needs, so as to realize real precision marketing.

\subsection{Establishing Information Base of Target Group}

In the new era, the information resource is an important capital for the survival and development of an enterprise, an important reference for analyzing customers' demands, and also the basis content to realize precision marketing [9]. Merchant can correctly collect customers' consumption records, basic information, browsing tracks, goods purchased and other information through big data technology. Through the big data technology, enterprises can store, dig, analyze and use customers' consumption time, frequency, amount and other contents, depict customers' specific profiles and help retail enterprises to accurately dig out valuable customers' information. On this basis, enterprises can realize good marketing results through data-driven marketing.

\subsection{Realizing Accurate Market Positioning}

After establishing the corresponding data base of target groups, enterprises also need to realize accurate market positioning. Retail enterprises must realize that any goods will not completely meet customers' preferences and demands in the actual application process. Therefore, enterprises must definitely locate sales target of goods. Firstly, an in-depth analysis on consumer group according to different situations of customers is required to choose a specific target market and realize detailed precise positioning. It is an importance part of precision marketing. In the digital marketing mode, retail enterprises can better divide the target customer groups with the help of big data technology, further improve goods according to customers' demands to meet consumer group's demands to the maximum extent, and realize the real market positioning [10].

\subsection{Providing Personalized Product Marketing}

From the future development trend, future consumption trend will turn to direction of personalization and 
E-commerce. Moreover, with the comprehensive popularization of Internet technology, people's demands on personalization and specialization will be further intensified in the future [11]. In fact, the retail industry is a complicated industry because it needs to not only ensure low cost while realizing high return, but also take customers' personalized demands into full consideration. Thus, enterprises may give up some of their rights appropriately to reduce goods costs while meet customers' personalized demands at the same time [12]. For example, IKEA lets its clients and customers to collate furniture freely, meet customers' demands to the maximum extent, realize maximize economic benefits and customer value, let customers to choose goods they need, and finally realize personalized product services.

\subsection{Precisely Pushing Goods for Customers}

In the process of using big data technology, retail enterprises can use this technology to dig data deeply, for example, inferring the consumption trend in the future and the clear uses portrait. Then, information of related goods can be pushed to those users who may need such information in the near future, to improve marketing effect and customer satisfaction [13]. For instance, in the E-commerce Taobao, if a customer purchases books related to bake, information of goods such as bake-ware and oven will be pushed to him/her in the coming few days. This push way can meet customers' needs and also improve the marketing effect fundamentally. Furthermore, it is difficult for many retail enterprises to contact with customers in the process of top-level design and front-line employees are not able to make marketing decisions. For this, big data technology can be used to collect and organize sales situations, including salable and unsalable goods, inventory data, sales data and other important information. It can ensure that enterprise management can know goods' selling situation and adjust goods structure timely, to truly realize the marketing target oriented at customers' demands [14]. As can be seen from Figure 1, the growth rate of the proportion of online retail in total retail sales in China shows a downward trend, indicating that the dividend of online retail sales in China is declining.

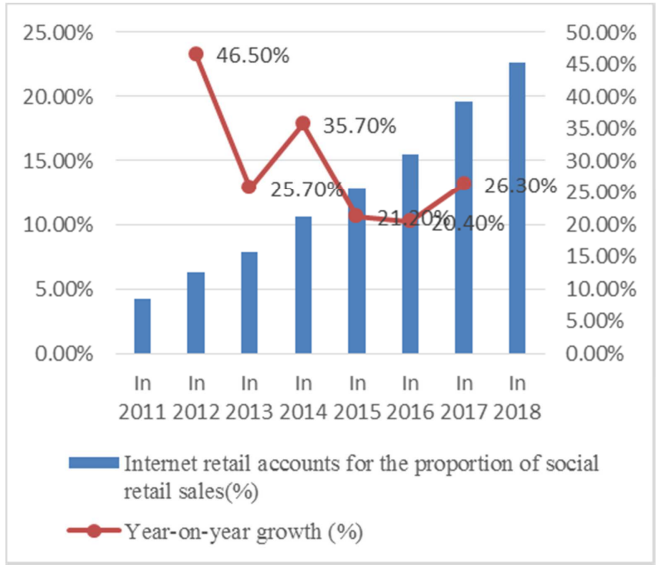

Figure 1. The proportion and growth rate of China's online sales to total retail sales in 2011-2018 (unit:\%).

\section{Specific Precision Marketing Application Cases Based on Digital Marketing Mode}

Through the analysis above, the precision marketing strategy of the retail industry is clear. In actual application, the realization method of precision marketing in the retail industry needs further analysis to effectively increase the sales volume of the retail industry.

\subsection{Customer Segmentation in Marketing}

The most important part in precision marketing is to fully analyze customers' consumption behaviors. Data mining technology is required to subdivide customers' consumption behaviors. According to Pareto's Law of $80 / 20$, important customers who can create profits for enterprises account for $20 \%$ of all customers while $80 \%$ of enterprises' profits are created by these customers. Enterprises can get the optimal returns in limited resource consumption as long as they can seize these customers. Therefore, in the practical application process of precision marketing for retail enterprises, enterprises must conduct customer segmentation, the first step for precision marketing. For example, Suning.com, in the process of analysis on customers' behaviors, establishes classification and regression tree (CART) to determine values of different customers, targeted on purchase materials of these customers according to their consumption times, types, last consumption time, consumption amount, consumption frequency and consumption cycle. Only on this basis can the importance degree of customers be ensured.

According to Pareto's Law of 80/20, the most important thing is that value customers in the retail industry are $20 \%$ important customers. These customers are also the most ideal, and retail enterprises need to attach attention in maintaining these customers in the process of marketing. The second is the sub-valuable customer. Retail enterprises often lose these customers in the process of marketing. And during the consumption process, these customers have low loyalty and are easy to be tempted by other competitors. Thus, retail enterprises should take care of these customers as much as possible to avoid these customers from being attracted by competitors. However, the proportion of the abovementioned two kinds of value customers is small, and potential value customers account a lot [15]. If retail enterprises can stimulate the purchasing power of these customer through effective marketing strategies, these potential value customers are likely to turn to value customers. In addition to the said three kinds of customers, enterprises still have some low value customers in the process of practical application. Enterprises do not need pay too much attention to these customers because it is hard to impress these customers through marketing strategies. All in all, the retail industry can formulate targeted marketing decisions according to the client base to provide retail enterprises with more reliable support. 


\subsection{Market Basket Positioning}

The retail industry not merely analyzes customers' consuming behaviors in the process of data mining. The essential purpose is to provide value customers with the top-quality services and realize positive interaction. Different from the category management where more attention is paid to suppliers, the precision marketing mainly faces customers and focuses on customers' demands at first time. Enterprises must pay active attention to the trend of customers who buy more frequently, and, on this basis, actively communicate with suppliers to realize higher customer satisfaction and form a sound cycle. It is to further analyze and research customer value and further divide customers' value potentiality on the basis of customer segmentation. Meanwhile, it also carries out positioning analysis on customers' market basket. This basic data mining can form specific understanding on goods positioning and the mode of cross-selling after getting accurate information just by simple statistical analysis, so as to increase effectively sales revenue. For example, many customers will purchase other items when they buy certain item. Then, if the two goods are put in the same position, the sales volume of these two goods will be further improved. Another example is that there are purchase packages in the Taobao platform. If merchant put two or more goods of the same type or in the same nature together to form a specific purchase package, the sales volume of these two goods will also be further improved.

\subsection{Targeted Customer Marketing}

On the basis of fully implementing the two applications of customer segmentation and shopping basket analysis, retail enterprises also need to realize the targeted marketing. Enterprises should make full use of neural network model, differential regression analysis technique (DRA) and decision-making tree etc. to dig out customers' information including age, income and life habit etc. and realize personalized product recommendation to a certain customer. Besides, the targeted marketing and promotion method can increase cross-selling opportunities and let retail enterprises be prepared for targeted marketing. On this basis, the formulation of product marketing and promotion shall be in accordance with the needs of customers. The maximization of enterprise profit is the fundamental core objective of retail enterprises to conduct targeted marketing. In the new era, the targeted marketing can solve promotion problems in the retail industry to the maximum extent. Retail enterprises need to gather and classify customers with different characteristics on the basis of corresponding sales data arranged firstly; then, form different customer bases to identify customers with different characteristics; finally, design different promotion plans to deliver different products and services to different customer bases, so as to meet customers' differentiated demands to the maximum extent.

\section{Conclusion}

To sum up, a new marketing trend is emerging in the retail industry with the integrated development of big data technology and the gradual establishment of the digital society. If retail enterprises do not want to be "abandoned" by the market, retail enterprises must break through the shackles of traditional marketing concepts and actively implement the precision marketing to effectively improve their core competitiveness. The long-term sustainable development among retailers, suppliers and customers can be realized by using data technologies, changing traditional marketing modes, accurately gathering precision marketing resources to valuable customers and establishing a new marketing mode.

\section{References}

[1] Binbin Zheng. Research on the Influencing Factors of Store Creativity in the Retail Digital Age [J/OL]. Business Economic Research, 2019 (05): 66-69 [2019-03-14]. http://kns.cnki.net/kcms/detail/10.1286.f. 20190305.1336.036.html.

[2] Feng Geng, Shenghua Xia, Tao Wu, Zhihui Wen and Yuangang Zhu. Digital transformation should deal with the cold winter of retail industry $[\mathrm{J}]$. Software and integrated circuits, $2019(01)$ : 60-63.

[3] Zheng Zhao. Suning Intelligent Retail Practitioner from Digital to Intelligent [J]. Business School, 2018 (08): 91-92.

[4] ZijianZ hang, Chuanli Xue. Study on Supply Chain Optimization of Retail Enterprises under Full Channel Model [J]. Industrial Economic Forum, 2016, 03(04): 468-476.

[5] Fabin Zhao. Digital transformation of service retail enterprises [J]. Digital Communication World, 2016 (S1): 48-49.

[6] Liang Su. The digital retail strategy of Five-Star Electrical Appliance Store [J]. Household Appliances, 2016 (01): 76-77.

[7] Editorial Department. Digital Retail [J]. China Business, 2015 (05): 62-63.

[8] Liang Dong. Design and Implementation of Precision Marketing System for Retail Enterprises Based on Membership Consumption [D]. Shandong University, 2018.

[9] Binbin Zhu. Exploration of Precision Marketing in Traditional Retail Industry Based on Big Data [J]. Management Observation, 2018 (18): 24-25+30.

[10] Qianlin Ye. Precision Marketing Analysis and Application Research of Commercial Banks Based on New Retail Model [D]. South China University of Technology, 2018.

[11] Qing Hu. Data Mining and Precision Marketing of Retail Customers [J]. Financial Science and Technology Era, 2017 (12): $18-24$

[12] Lijun Hu. Application Analysis of Precision Marketing in Retail Enterprises [J]. China Market, 2017 (34): 105-106.

[13] Haifeng Wang and Xiaoqian Lu. Precision Marketing of Traditional Retail Industry Driven by Big Data - Take Chaoyang Joy City as an Example [J]. Industrial \& Science Tribune, 2016, 15 (17): 20-22. 
[14] Xi Chen. Discussion on Precision Marketing of Local Retail Industry from the Perspective of Data Mining [J]. Journal of Commercial Economics, 2016 (11).
[15] Jin Zhou, Hui Liu. How to enhance the competitiveness of retail business through customer relationship management and precision marketing under the new normal situation [J]. Financial electronization, 2016 (10): 42-43. 